\title{
OECONOMIA
}

COPERNICANA

\section{VOLUME 10 ISSUE 2 JUNE 2019}

p-ISSN 2083-1277, e-ISSN 2353-1827

www.oeconomia.pl

\section{ORIGINAL ARTICLE}

Citation: Zajkowski, R., \& Domańska, A. (2019). Differences in perception of regional proentrepreneurial policy: does obtaining support change a prospect? Oeconomia Copernicana, 10(2), 359-384. doi: 10.24136/oc.2019.018

Contact to corresponding author: robert.zajkowski@umcs.lublin.pl; Maria Curie - Sklodowska University in Lublin, Pl. Marii Curie Skłodowskiej 5, 20-031 Lublin, Poland

Received: 16.11.2018; Revised: 25.03.2019; Accepted: 18.04.2019; Published online: 22.05.2019

\author{
Robert Zajkowski \\ Maria Curie - Sklodowska University in Lublin, Poland \\ (iD) orcid.org/0000-0002-0021-7977 \\ Ada Domańska \\ Maria Curie - Sklodowska University in Lublin, Poland \\ (iD) orcid.org/0000-0002-8239-4319
}

\section{Differences in perception of regional pro-entrepreneurial policy: does obtaining support change a prospect?}

\author{
JEL Classification: $L 26 ; P 48 ; R 11 ; R 58$
}

Keywords: entrepreneurship; entrepreneurial ecosystem; regional development; regional economic policy

\begin{abstract}
Research background: In the paper, we presented a most crucial aspect of the entrepreneurial ecosystem in a regional context that seems to be more visible than the general approach. The role of entrepreneurs and support institutions as one of the main actors of a regional entrepreneurship ecosystem was underscored. We also stressed the significance of entrepreneurs' opinions related to Business Support Institutions (BSI) as sources of feedback and potential boosters of delivery and promotion that can be used by regional stakeholders and policymakers.

Purpose of the article: The aim of this paper is to investigate significant differences in a perception of regional pro-entrepreneurial institutions between businesses that obtained or did not obtain support.

Methods: Our study is based on data collected in Lubelskie Voivodeship, hence they refer to a single region in Poland. The sample totalled 386 responses, and we conducted numerical analyses by using the logit linear regression model. As the dependent variable, we used a dualvariable (not supported; supported) that describes two groups of enterprises, i.e. those that do not get and those that got some sort of public support. As independent variables, we adopted 18
\end{abstract}


factors that depict ordinary scale perception of various aspects of regional pro-entrepreneurial policy.

Findings \& Value added: Analyses revealed nine statistically significant relationships between perception of regional BSI impact on enterprises functioning and regional entrepreneurial ecosystem depending on whether particular enterprises got or did not get support, e.g. a favourable experience in obtaining support boosts positive perception that support from BSI influences positively the decision to set up one's own business. BSI at Lubelskie Voivodeship acts in favour to create bonds between enterprises, and support from BSI increases opportunities to survive in the market. Moreover, supported enterprises perceived better aspects, such as positive influence on enterprises' innovativeness thanks to BSI, and more are convinced that support programmes of BSI are available for a broad group of companies.

\section{Introduction}

Entrepreneurship is one of the most crucial factors of regional development, which influences competitiveness through absorption of specific regional development-driven assets. Local authorities, due to creation of regional economic policy, play an important role in entrepreneurship development. They should frame an effective entrepreneurial ecosystem as a platform for advancement of various kind of businesses (Acs et al., 2013; Feldman 2014). Additionally, a business support policy has to be realised in a long-term perspective and adjusted strictly to the local circumstances and resources (Fritsch, 2013; Tsvetkova, 2015; Johannisson, 2011). But with scientific evidence and theoretical studies, business entities assess the effectiveness of an entrepreneurial ecosystem from the perspective of their own experience and knowledge. More profound analyses allowed us to identify a research gap related to differentiation in the perception of various aspects of regional pro-entrepreneurial policy between businesses that are being supported or not.

The main purpose of the paper was to identify significant differences in the perception of regional pro-entrepreneurial policy between businesses that obtained or did not obtain support.

The primary data were collected with a survey conducted in 2017 (CAWI and PAPI techniques). After rejection of incomplete or incorrectly completed questionnaires, the sample totalled 386 enterprises. In numerical analyses, we used a dual-variable (0-not supported; 1 -supported). As independent variables, we adopted 18 factors that depict ordinary scale perception of various aspects of regional pro-entrepreneurial policy. The variables were complemented with two controls. On this basis, we calculated a logit regression model. The model's parameters are statistically significant.

Based on the model, we identified nine statistically significant differences in the perception of regional pro-entrepreneurial policy between surveyed groups of companies. The findings confirmed our hypothesis and 
fulfilled partly the identified research gap. Our results generally confirmed that companies that are experienced in obtaining support perceive proentrepreneurial policy as relatively more effective and accessible than firms that did not get public support. The added value of our findings refers to potential adjustment of regional information and a promotion policy that could encourage companies that avoid undertaking steps to achieve some forms of public support.

We proceed as follows. First, we studied the literature and assembled a number of findings associated with general entrepreneurial ecosystem and organisations, underscoring a role of institutions in a regional context and the significance of entrepreneurs' opinions as feedback for stakeholders about how to shape a pro-entrepreneurial milieu. Subsequently, we presented the background of our research that allows us to formulate hypotheses and methodology. Next, we presented raw results based on the research model, conducted discussion and formulated conclusions for theory and praxis.

\section{Literature review}

\section{Entrepreneurial ecosystem approach}

There is a growing recognition that if entrepreneurship theory is focused only on the entrepreneur, that may be too narrow an approach. Due to this, the concept of entrepreneurial ecosystems has gained popularity in recent years. But an entrepreneurial ecosystem has not been described sufficiently by researchers or practitioners. This concept must be deeply analysed and developed to determine what it actually stands for. Entrepreneurial ecosystem was originally defined by Dubini (1989). Its elements include a strong business infrastructure, a diversified economy with access to investment capital and a culture supporting entrepreneurship. In addition, there are strong incentives to create new ventures supported by public policy. An early concept was adopted from biology to economics. Moore argued that "business ecosystems condense out of the original swirl of capital, customer interest, and talent generated by a new innovation, just as successful species spring from the natural resources of sunlight, water, and soil nutrients" (Moore, 1993). Recently, research on entrepreneurial ecosystems has been growing (Napier \& Hansen, 2011; Malecki, 2011; Feld, 2012). The entrepreneurial ecosystem approach has been developed by different authors, with no common definition. Acs et al. (2014) defined entrepreneurial ecosystems as a "dynamic, institutionally embedded interaction between 
attitudes, abilities and aspirations of entrepreneurs, by individuals, which drives the allocation of resources through the creation and operation of new ventures". Many authors emphasize the interdependence between ecosystem actors by including entrepreneurs, suppliers, buyers, entrepreneurs' organisations, institutions supporting entrepreneurship and local authorities. Participants in the system that undertake joint actions formally and informally combine, mediate and regulate the local environment, thereby enabling entrepreneurial activity (Stam, 2014; Mason \& Brown, 2014; Motoyama \& Knowlton, 2017). Interactions allow creating new ideas and more effective policies (Zacharakis et al., 2003; Deloitte, 2012). To take advantage of the opportunities, the entrepreneur needs access to all the ecosystem framework conditions that are conducive to business activity by limiting barriers (Levie \& Autio, 2014). Drawing on these studies, Spigel (2017) defines entrepreneurial ecosystems as "combinations of social, political, economic, and cultural elements within a region that support the development and growth of innovative start-ups and encourage nascent entrepreneurs and other actors to take the risks of starting, funding, and otherwise assisting high-risk ventures".

Of course, the initial biological concept cannot be taken too literally in the context of entrepreneurial ecosystems (Stam, 2015). The system includes the stock of institutions and the stock of entrepreneurship. In contrast to biological systems, participants in the entrepreneurial ecosystem are aware of their actions. They can take steps to improve the conditions for the functioning and development of entrepreneurship (Walker et al., 2004). This concept assumes interaction between participants through the flow of knowledge. Importantly, entrepreneurship takes place in a community of interdependent entities (Roundy et al., 2016).

Successful ecosystems are not defined by high rates of entrepreneurship, but rather by how the interaction between these attributes creates a supportive regional environment that increases the competitiveness of new ventures (Spigel, 2017). There is a distinction between the traditional measures of entrepreneurship, such as the number of self-employed or the number of new enterprises. Conceptually, more adequate measures of entrepreneurship are the number of innovative and growth-oriented entrepreneurship (Shane, 2009; Stam et al., 2012; Henrekson \& Sanandaji, 2014). Thus, the entrepreneurial ecosystem concept often narrows entrepreneurship to "highgrowth start-ups", claiming that this type of entrepreneurship is an important source of innovation, productivity growth and employment (World Economic Forum, 2013; Mason \& Brown, 2014). In addition to Feld (2012) and Stam (2014), Mason and Brown (2012) placed companies with high growth with significant management functions that are undertaking re- 
search and development at the centre of the entrepreneurial ecosystem (Bosma \& Stam, 2012). The literature indicates that ambitious entrepreneurs more often achieve significant growth, innovation or internationalization than the "average" entrepreneur. Therefore, it is important to support such entities. This approach is too narrow, because there are other forms of productive entrepreneurship, for example, entrepreneurial employees. Such employees seem particularly important for the creation of new values in developed economies (Bosma et al., 2012; Stam, 2013; Bosma et al., 2014). The entrepreneurial ecosystem approach thus begins with the entrepreneurial individual instead of the company and focuses on the external business environment. This approach differs from other concepts in that the entrepreneur is the focal point, not the enterprise.

\section{Regional context}

In works from the 1990s, the concept of an "entrepreneurial environment" or ecosystem was used to explain the influence of regional economic and social factors on the entrepreneurship process. Many studies indicate that the entrepreneurial ecosystem creates value at the regional level (Fritsch, 2013; Tsvetkova, 2015). It is claimed that in dynamic ecosystems, companies have greater development opportunities compared to companies operating in other locations (Rosted, 2012).This means that the location is important in building the ecosystem.

The regional context related to cultural, social, political, and economic structures and processes related to a given place have an impact on the entrepreneurial ecosystem (Johannisson, 2011). This means that systems are geographically related (Stam \& Bosma, 2015). Therefore, in various locations, one's own entrepreneurial ecosystems can be built based on an analysis of the strengths and weaknesses of the territory that can encourage the appearance of successful business concerns.

Isenberg (2010) postulates that "there is no exact formula for creating an entrepreneurial ecosystem, there are only practical, imperfect road maps". Different ecosystems will have different results in different parts of the world, depending on various factors and institutions. This means that it is not possible to accurately copy the existing entrepreneurial ecosystem elsewhere by simply replicating its features. Only a built ecosystem based on a specific territorial reality enables productive entrepreneurship in a given territory. This approach suggests that building entrepreneurial activity cannot be seen in isolation from the region. 


\section{Entrepreneurial ecosystem domains}

Many studies attempt to identify key elements of a successful entrepreneurial ecosystem (Isenberg, 2010; Motoyama \& Knowlton, 2017; Spigel, 2017; Brown \& Mason, 2017). The entrepreneurial ecosystem framework determines who is becoming an entrepreneur and how different domains affect entrepreneurial activities and ecosystem results (Andersson \& Koster, 2011; Autio et al., 2014).

Systems are very diverse, and different elements can determine the success of local entrepreneurship, which actually brings positive social and economic effects. Therefore, concepts have been developed to enable understanding of various entrepreneurial ecosystems and to outline a general framework for the elements that are decisive for their development.

Isenberg developed a particularly influential approach in conjunction with the Babson College Entrepreneurship Ecosystem Project, which began to be referred to as the "entrepreneurial ecosystem strategy for economic development" (2011). Although each ecosystem of entrepreneurship is unique and consists of innumerable elements, one can identify a number of general factors determining its efficiency. According to Isenberg (2010), there are six domains of entrepreneurship: policy, finance, culture, supports, human capital and markets.

The policy domain includes government institutions supporting entrepreneurship and regulatory authorities responsible for implementing incentives to start businesses and removing barriers for business development. In the sphere of finance, private institutions deal with entrepreneurship financing, such as business angels, venture capital funds and seed capital. Culture embraces the social characteristics of communities which determine that a given community behaves in an entrepreneurial way. Society's perceptions of entrepreneurs are also important. As part of the support, there are institutions that act as stimulators of entrepreneurship, such as incubators, technology parks, foundations supporting entrepreneurship and companies providing services to enterprises such as accounting and legal firms that support the creation of new companies and the development of existing ones. Human capital includes both those professionals who have accumulated their skills through entrepreneurial education and the massive workforce that can be used for economic development. The market domain means that there must be a mass of consumers ready to buy new products and distribute them through a national and international network of contacts (Arruda et al., 2013).

These six elements are the main attributes of entrepreneurial ecosystems, but they should rather be understood as the main factors that help 
create conditions for business operations and provide external resources that increase the competitiveness of new ventures (Spigel, 2017).

Identification of general causal pathways is therefore of limited value. Due to this, the meaning of context is emphasized, that is, every ecosystem emerges in a unique set of conditions and circumstances. Not all domains are necessary for the development of a thriving ecosystem. There are examples of successful entrepreneurial ecosystems that do not have one or more of these elements. Broad studies show that in three domains - policy, finance and support - the key role of the institution is emphasized. We can go beyond this and claim that one of the main features of wellfunctioning entrepreneurial ecosystems is the existence of institutions that build potential for regional economic development (Audretsch \& Lehmann, 2005; Acs et al., 2013; Feldman 2014).

\section{Institutions as an element of entrepreneurial ecosystem}

As noted, numerous studies have been carried out to identify the components of a well-functioning entrepreneurial ecosystem. The entrepreneurial ecosystem framework conditions consist of the social (informal and formal institutions) and physical conditions enabling or constraining human interaction. Systemic conditions are the heart of the ecosystem and include networks of entrepreneurs, leadership, finance, talent, knowledge, and support services (Stam \& Spigel, 2016). They are named generally Business Support Institutions (Delic et al., 2012), Business Environment Institutions (Glabiszewski et al., 2018), or Entrepreneurship Support Institutions (Korent et al., 2015). We decided to adopt the notion of Business Support Institutions (BSI) to describe entrepreneurial ecosystem institutions.

The World Economic Forum study (2013) determined that access to markets, human capital and finance is the most important factor that developed ecosystems. But in fact, human resources and finances depend to a large extent on institutions functioning within a given ecosystem (Acemoglu et al., 2005). It is postulated that if all regions had similar entrepreneurial resources, their translation into economic growth would be different due to the different levels of development of the institution. Regions with weak institutions have little chance of creating productive entrepreneurship (Baumol \& Strom, 2007). Hence, the entrepreneurial ecosystem works well if there is a sufficient diversity of institutions that support entities operating in it and consequently create optimal interaction between these elements (Audretsch \& Lehmann, 2005; Zhang \& Li, 2010). Institutions supporting entrepreneurship increase the cohesion of intentions, behaviours and results of participants of the entrepreneurial ecosystem, causing it to function as 
a co-dependent system, not a loose collection of entities (Roundy et al., 2017).

For an ecosystem to be successful, large established institutions should be supportive. Business support institutions organise, within the broad institutional system of general support, the distribution sub-systems of particular support forms and instruments aimed at entrepreneurs (Kenney \& Patton, 2005; Patton \& Kenney, 2005). This includes organisations in different legal forms that render services called business support services. Such services, originating in a public policy initiative, aim to assist enterprises or entrepreneurs to develop their businesses successfully and to respond effectively to the challenges of their businesses, both socially and physically (Commission of the European Communities, Brussels, 2001). Also, support institutions organise a large number of events in which entrepreneurs and the community can connect and engage with very visible and authentic participants. Prosperous ecosystems depend on a deep, well-connected community of newly created enterprises and entrepreneurs, as well as involved and visible investors, advisers, mentors and supporters. The common denominator seems to be the fact that entrepreneurs create a new value when there is an extensive network of institutions supporting entrepreneurship in a given region. That is why our approach follows Isenberg (2010), but we describe relationships within the three domains of ecosystem framework conditions - policy, finance and support - related to the operation of institutions supporting entrepreneurship. This approach captures the notion that in the entrepreneurial ecosystem, the ultimate impact of individual-level action is regulated by the institutional framework conditions rather than the economic growth that follows.

\section{Entrepreneurs' opinions}

Many scholars raise the question of how to measure the activity of the entrepreneurial ecosystem. Along with the rapid dissemination of efforts to build entrepreneurial ecosystems, it is natural to wonder what results to follow. That is why various measures are adopted. As noted, simple measures related to the number of enterprises are insufficient. Regional entrepreneurial policies are currently undergoing a transition from increasing the amount of entrepreneurship to the quality of entrepreneurship. Some ecosystems are focused around a specific type of company. Regions see the entrepreneurial ecosystem as a marketing effort and focus on the specific type of entity they hope to attract to their area (Bell-Masterson \& Stangler, 2015). 
Considering that one of the measures of the entrepreneurial ecosystem is the development of a network of institutions supporting entrepreneurship, policy-makers, supporters and entrepreneurs should take into account the local nature of the ecosystem. When creating or promoting new programs to support entrepreneurship, decision-makers should take into account local conditions and should consider what types of entrepreneurs are already served by existing programs and what types of entrepreneurs still are underserved (Motoyama et al., 2014). There must be many programs and activities that appeal to all levels of entrepreneurs and meet their needs. This approach starts with an entrepreneurial actor, because entrepreneurship is not only the result of the system, but also entrepreneurs are important players in creating an ecosystem and maintaining it. It is important to take into account the needs of entrepreneurs in the process of making decisions (Feld, 2012).

This means that to build and maintain a business ecosystem that is appropriate for local enterprises, decision-makers should listen to the opinions of the enterprises themselves and build, on this basis, entrepreneurshipsupporting programs. Considering this, we focus on opinions of enterprises on the functioning of the entrepreneurship support system, which is an important element of the entrepreneurial ecosystem. The opinions of enterprises as the main actors of the ecosystem are extremely important. In addition, the latest literature on entrepreneurial ecosystems underscores the important role of key ecosystem stakeholders, mainly the so-called entrepreneurial leaders (Feld, 2012).

Leadership provides direction and role models for the entrepreneurial ecosystem. This leadership is critical in building and maintaining a healthy ecosystem. Leaders are a strong group of entrepreneurs who are visible, available and engaged in the region. Entrepreneurs with a long-term commitment to the ecosystem are often best positioned to recognize the opportunities and restrictions of the ecosystem and to deal with them together with entrepreneurship support institutions. Therefore, entrepreneurs who have benefited from entrepreneurship support institutions belong to a group of particularly involved entities that has adopted a long-term perspective related to a given region. This means that their opinions about the activities of the entrepreneurial ecosystem, and especially support services, are the most important. That is why, apart from the opinions of all companies, we pay special attention to the opinion of enterprises that used the support of institutions that support entrepreneurship. Moreover, based on our regional study, we compare whether getting support as an act of cooperation between entrepreneurs and BSI changes subjective perceptions about those institutions. 


\section{Research methodology}

\section{Characteristic of Lubelskie Voivodeship}

Taking into consideration that with entrepreneurial ecosystem theory. regional circumstances are crucial for enterprises development, we decided to conduct our study in Lubelskie Voivodeship, which is among the least developed regions of Poland and the European Union. The data presented in Table 1 indicate that this region presents the poorest performance among other regions of Poland in GDP per capita in euros and gross value of fixed assets in enterprises per capita. Furthermore, in total length of expressways and motorways per $1.000 \mathrm{~km} 2$, investment outlays per capita, value of foreign capital per capita, it ranks among the last places.

Taking into account as well statistical figures as regional traits and features, we recognize Lubelskie Voivodeship as a "lagging region". To this group can be added regions that are provincial (often border regions), remote from central regions, with relatively poor technical infrastructure. The specificity of this area is a lack of big cities with metropolitan functions and lack of well-developed, attractive and diverse industry as a pivotal stimulus for outside investments. Additionally, typical features of lagging regions include a poor $\mathrm{R} \& \mathrm{D}$ sector and institutional infrastructure, innovativeness and pro-entrepreneurial attitude. Consequently, well-skilled and educated workers migrate to regions with better opportunities.

To the crucial factors of regional development, besides communication infrastructure, investment areas, natural resources, engagement of local workforce, and implementation of innovations, etc., support for SMEs and regional institutional infrastructure can be included. Unquestionably, an active role of BSI is required. Therefore, it was our major reason and aim to conduct a study devoted to recognition of significant differences in perceptions of regional pro-entrepreneurial institutions between businesses that obtained or did not obtain support.

However, the active role of BSI is pointless without cooperation among enterprises and institutions. Cooperation is a relationship in which individuals, groups and organisations interact by sharing or transferring complementary skills and resources, and their development benefits both sides (Gnyawali et al., 2006). The ability to cooperate leads to problem-solving, development of processes and mutual learning and finally to achievement of different enterprises' goals (Lunnan \& Haugland, 2008; Kale \& Singh, 2009). Moreover, cooperation, especially fruitful cooperation, must create a positive image of BSI in the opinion of the enterprises. Considering this 
point, we have formulated two hypothesis connected with changes in perception of BSI by enterprises that got support.

$\mathrm{H}_{1}$. Enterprises perceive support from BSI as a source of positive impact on entrepreneurial ecosystem development.

$\mathrm{H}_{2}$. Enterprises perceive support from BSI as a source of positive impact on direct business processes.

\section{Data collection}

Our data were derived from a random sample of companies with headquarters in the Lubelskie Voivodeship. The data were collected with Computer Assisted Web Interview (CAWI) and Paper and Pencil Interview (PAPI) techniques. Additionally, the method of the Mixed Mode Survey Design was implemented (Hox et al., 2008; Dillman et al., 2009). Its essence is to collect the same types of information from various groups of people using different survey techniques. Therefore, internet questionnaires were sent via emails (links) to 7.940 business entities and simultaneously through Facebook to a further group of 200 entrepreneurs. Due to the low percentage of the questionnaires which were completed and returned i.e. $3.88 \%$, we deliberately chose to use PAPI technique to reach out to firms that are not keen to fill out internet questionnaires. After elimination of incomplete or incorrectly filled questionnaires in the database, the sample totalled 386 responses. It should be noted that the original data were gathered as part of a larger research project, The model of institutional supporting entrepreneurship in the region with pro-development aspirations.

The enterprises have been selected for the study using a nonprobabilistic method, i.e. not based on the principles of probability but on subjective inclusion of entities to the sample - purposing sampling (Tongco, 2007). However, by implementing quota sampling, the structure of the sample reflects the structure of the population in terms of the law form of the enterprise and sub-regional division (Test $\mathrm{chi}^{2} \mathrm{p}=0.456$ and $\mathrm{p}=0.513$ ). Surveyed enterprises declared revenues from 10,000 PLN to $38,000,000$ PLN, with average 634,510 PLN. Table 2 presents other characteristics of the sample.

The majority of enterprises declared services as their domain of activities $(71,76 \%)$. A significant percentage indicated trade (commerce) as their primary activity $(37,56 \%)$, and $17,36 \%$ deal with industry. It should be noted that part of the companies declared more than one type of activity; therefore, the sum of percentages exceeds $100 \%$. Additionally, we extract- 
ed from our sample two sub-samples, those that did not get and those that got some sort of public support. We used this division as the dependent variable. Enterprises that did not get support totalled 267 (69\%) entities, and the other group amounted to 119 (31\%) firms. This unbalanced division aligns with other Polish studies. For example, a survey conducted in 2017 by Glabiszewski et al. (2018) in all Polish regions revealed that more than $55 \%$ of firms identified lack of cooperation with government institutions, $63 \%$ noted lack of cooperation with units of the sphere of $R \& D$, and $60 \%$ pointed out lack of cooperation with institutions engaged in direct business support. Similar figures are presented by the Polish Agency for Enterprise Development (2016) ${ }^{1}$. It seems to be typical that a minority of Polish SMEs cooperate with BEI in some way. But general research revealed that such services are not popular among SMEs (Dyer \& Ross, 2008; Hakimin, 2010; Lewis et al., 2007).

Finally, our sample appears to be relatively heterogeneous and allows us to conduct multifaceted analyses referring to perceptions of various aspects of regional entrepreneurial ecosystems.

\section{Model and variables}

Based on the collected data, we calculated a logit regression model. First, conceptually, we decided to analyse whether perception of regional Business Environment Institutions differs among companies that had access to some sort of public support or did not. Hence, in numerical analyses, as the dependent variable, we used a dual-variable (0-not supported; 1supported) that describes two groups of enterprises, i.e. those that did not get and those that got some sort of public support. As independent variables, we adopted 18 factors that depict an ordinary scale perception of various aspects of regional pro-entrepreneurial policy. All of them were adopted by Domańska and Zajkowski in their paper in $2013^{2}$. (The variables were complemented with two controls - number of employees (logarithms) and total revenue (logarithms)). Table 3 shows descriptive statistics for the independent variable and controls.

Cronbach's alpha coefficient for independent variables $\mathrm{x}_{1}-\mathrm{x}_{18}$ (controls were excluded) achieved 0.92. This means that internal consistency of a scale is high and the items in a test measure the same construct (Miller, 1995; Cohen, \& Swerdlik, 2010; Tavakol, \& Dennick, 2011). All variables $\mathrm{x}_{1}-\mathrm{x}_{18}$ were measured on an ordinary scale from $1-$ strongly disagree to 5

\footnotetext{
${ }^{1}$ https://www.parp.gov.pl/publications?language=en (5.01.2018).

${ }^{2}$ http://www.jmf.wzr.pl/pim/2013_1_3_9.pdf (5.01.2018).
} 
- strongly agree with given perception of regional Business Environment Ecosystem or Institutions. Additionally, we included two controls: $\mathrm{x}_{19}$ number of employees (logarithms) and $\mathrm{x}_{20}$ revenue in last year (logarithms). Table 4 presents the correlation's matrix between independent variables.

Further statistical analyses were carried out by implementing logistic regression models (see Table 5).

The calculated model is well fit (Hosme-Lemeshow test $\mathrm{p}=0.623$ non to reject $\mathrm{H}_{0}$ is required; $-2 \mathrm{Log}$ likelihood: 303,53 ; Cox \& Snell $\mathrm{R}^{2}$ : 0.298 ; Nagelkerke $\mathrm{R}^{2}: 0.420$; Chi-square $\mathrm{p}=0.000$ ) and allows us to draw definitive results and conclusions (significance level $\mathrm{p}=0.05$ was accepted).

\section{Results}

Analyses revealed nine statistically significant relationships between perception of regional BSI impact on enterprises' functioning and regional entrepreneurial ecosystem depending on whether particular enterprises got or did not get support. A favourable experience in obtaining support boosts positive perception that support from BSI influences positively the decision to set up one's own business $\left(\mathrm{x}_{1}\right)$. BSI at Lubelskie Voivodeship acts in favour to create bonds between enterprises $\left(\mathrm{x}_{2}\right)$, and support from BSI increases opportunities to survive in the market $\left(\mathrm{x}_{3}\right)$. Moreover, supported enterprises perceived better aspects such as positive influence on enterprises' innovativeness thanks to BSI ( $\left.\mathrm{x}_{9}\right)$, and more were convinced that support programmes of BSI are available for a broad group of companies $\left(\mathrm{x}_{16}\right)$ and that members of staff in BSI are engaged and willing to lend support $\left(\mathrm{x}_{17}\right)$. By contrast, enterprises that obtained support are less prone to claim that support from BSI increases opportunities to capture outside investors $\left(\mathrm{x}_{5}\right)$, that BSI influences development of Lubelskie Voivodeship $\left(\mathrm{x}_{12}\right)$ and that BSI in Lubelskie Voivodeship are keen to cooperate with each other $\left(\mathrm{x}_{14}\right)$.

First, we can conclude that obtaining support for enterprises changes general perceptions related to BSI. Our model showed that in nine out of eighteen surveyed areas (variables), differences in perception occurred that are statistically significant. Confirmed differentiations can be divided into two groups: aspects that refer to general entrepreneurial ecosystem functioning and those that affect directly entrepreneurs' operational processes. In the first group, there were both positive and negative perception changes of various aspects of BSI. Positive changes encompass such aspects as 
market survival $\left(\mathrm{x}_{3}\right)$, broad access to the support $\left(\mathrm{x}_{16}\right)$ and engagement and competences of BSI staff $\left(\mathrm{x}_{17}\right)$. A drop in the perception refers to influences of Lubelskie Voivodeship's development $\left(\mathrm{x}_{12}\right)$ and propensity to cooperate with each other $\left(\mathrm{x}_{14}\right)$. Consequently, Hypothesis $\mathrm{H}_{1}$ cannot be verified positively. Enterprises that had access to some sort of support in fact changed their opinions related to BSI, but changes are not all one-way.

Taking into account activities of BSI that refer to entrepreneurs' functioning directly, three were seen as better, i.e. sparking decisions to set up businesses $\left(\mathrm{x}_{1}\right)$, creating bonds between enterprises $\left(\mathrm{x}_{2}\right)$ and impact on innovativeness $\left(\mathrm{x}_{9}\right)$. One was perceived as worse: opportunities to capture outside investors $\left(\mathrm{x}_{5}\right)$. We assumed that involvement of outside investors occurs relatively seldom and is less important for companies than surviving in the market, innovativeness and business establishment. From this perspective, we suggest that Hypothesis $\mathrm{H} 2$ was confirmed.

\section{Discussion}

Boter and Lundstrom (2006) showed that the services offered by institutions are considered effective and workable if the utilisation rate was satisfactory. It seems to be typical of people's behaviour and perception that even if they had some troubles with their application for support, after a positive decision, they should be prone to "forgive" difficulties and utterly assess the institution rather well. We expected that in this case, we would observe something like the "halo effect", which was introduced to psychology by Thorndike in 1920, and which could be transferred to the processes of assessing general institutions (Rasmussen, 2008; Schneider et al., 2012). Specifically, we expected that if one feature of BSI is perceived well, this positive perception would be transferred to other features (activities, engagement etc.). But our findings did not confirm this phenomenon literally. It rather occurred that if the enterprises had narrow contacts with BSI, they know specificity of BSI and they are aware of their limitations than businesses are less prone to believe that BSI are able to influence directly the development of the region or to help identify potential investors. Moreover, due to permanent competition between BSI, these institutions are not inclined to cooperate. More often, they struggle to win the same UE funds (grants, projects, programmes) rather than cooperate to allocate resources in the best way. This competition or sometimes aggressiveness is of course observed by enterprises and transferred to their opinions about the unwillingness to cooperate. 
Importantly, the growing significance of the influence of public support on entrepreneurs' innovativeness, which is necessary to improve firms' competitiveness in the market, should be underscored (Ejdys et al., 2015; Daniluk, 2016). Moreover, Thurik et al. (2013) suggested that the role of regional policy is not to maximize a certain indicator of entrepreneurship, but to create a system in which productive entrepreneurship can flourish. Additionally, an impact of BSI as a potential organisation that consciously and subconsciously encourages entrepreneurs to tighten cooperation and create mutual bonds is supportive for regional collective learning. There are processes that reduce the uncertainty firms face in a rapidly changing technological environment, such a competence gap arising from the firm's limited ability to process and understand available information (Lorenz, 1996). It helps overcome internal coordination problems by constructing shared knowledge in the form of commonly understood rules and accepted procedures (Lazaric \& Lorenz 1997; Lawson, 1997). Finally, better understanding of business functioning conditions should encourage people to make the decision to set up their own businesses.

\section{Conclusions}

Taking into account both the theoretical background and the results of the study, we can make two recommendations. First, our contribution to the theory is that positive experience tied with cooperation between enterprises and BSI affect perception of those institutions in the group of companies. Generally, they are assessed better, but some fields are perceived as worse. Getting support moderates the perception of companies, but it is worth assessing whether these changes are stable und unchangeable over time or whether this is only a fleeting effect. This needs a more profound study. Another question is whether getting support sparks willingness of enterprises to take steps to obtain the next supportive products and services. On the basis of our study, these questions are unanswered.

Our findings can also be supportive for regional pro-entrepreneurial policy-makers and other groups of stakeholders. On the one hand, when they create local supportive policy, they should take into account local conditions and consider what types of entrepreneurs are already served by existing programs and what types of entrepreneurs still are underserved (Motoyama et al., 2014). On the other hand, policy-makers need to be aware that perceptions of enterprises after they are supported in some aspects act in favour of BSI and should engage those enterprises in the creation of informing policy and dissemination of BSI offers. We deeply believe that 
nobody is as convincing to other entrepreneurs as other entrepreneurs. Thus, entrepreneurs and entrepreneurships that get support can act as leaders (Feld, 2012) or best practitioners (Frese et al., 2014) that are visible, available and engaged in the regional development. Using their image can boost delivery and promotion related to regional entrepreneurial ecosystem and regional BSI activities. For entrepreneurs, this engagement can serve as non-profit advertisement, and in this way, the interests of both entities would be balanced.

Results presented above are not free from limitations. Due to technical and financial difficulties and demands empirical research was done only for a single region in a single country (Poland). Thus they reflect the regional specificity of one of the less developed areas in UE and they could differ between regions in Poland and other EU countries. Simultaneously, this limitation could be a springboard for further studies based on cross-regional or cross-countries analyses in this field. It is still open canvas how the Business Environment Ecosystem or Institutions are perceived in different regions.

\section{References}

Acemoglu, D., Johnson, S., \& Robinson, J. A. (2005). Institutions as a fundamental cause of long-run growth. In P. Aghion \& S. Durlauf (Eds.). Handbook of economic growth. Amsterdam: Elsevier. doi: 10.3386/w10481.

Acs, Z. J., Audretsch, D. B., \& Lehmann, E. E. (2013b). The knowledge spillover theory of entrepreneurship. Small Business Economics, 41(4). doi: 10.1007/ s11187-013-9505-9.

Acs, Z. J., Autio, E., \& Szerb, L. (2014). National systems of entrepreneurship: measurement issues and policy implications. Research Policy, 43(3). doi: 10.1016/j.respol.2013.08.016.

Andersson, M., \& Koster, S. (2011). Sources of persistence in regional start-up rates: evidence from Sweden. Journal of Economic Geography, 11(1). doi: 10.1093/jeg/lbp069.

Arruda, C., Nogueira, V. S., \& Costa, V. (2013). Brazilian entrepreneurial ecosystem of start-ups: analysis of entrepreneurial conditions in Brazil seen from the OECD pillars. Journal of Entrepreneurship and Innovation Management, 2(3).

Audretsch, D. B., \& Lehmann, E. E. (2005). Does the knowledge spillover theory of entrepreneurship hold for regions? Research Policy, 34(8). doi: 10.1016/j. respol.2005.03.012. 
Autio, E., \& Levie, J. (2014). Hard facts or soft insights? Fact-based and participative approaches to entrepreneurship ecosystems policy and management. Entrepreneurial Ecosystems, Innovation and Regional Competitiveness. 2014-1212 - 2014-12-13. Henley Business School, University of Reading. Retrieved form https://strathprints.strath.ac.uk/58813/.

Autio, E., Kenney, M., Mustar, P., Siegel, D., \& Wright, M. (2014). Entrepreneurial innovation: the importance of context. Research Policy, 43(7). doi: 10.1016/ j.respol.2014.01.015.

Baumol, W. J., \& Strom, R. J. (2007). Entrepreneurship and economic growth. Strategic Entrepreneurship Journal, 1 (3-4). doi: 10.1002/sej.26.

Bell-Masterson, J., \& Stangler, D. (2015). Measuring an entrepreneurial ecosystem. Kansas City: Kauffman Foundation Research Series on City, Metro, and Regional Entrepreneurship. doi: 10.2139/ssrn.2580336.

Bosma, N., \& Stam, E. (2012). Local policies for high-employment growth enterprises. In Report prepared for the OECD/DBA international workshop on highgrowth firms: local policies and local determinants. Copenhagen: OECD/DBA. doi: 10.1093/oxfordhb/9780199993307.013.14.

Bosma, N., Stam, E., \& Wennekers, S. (2014). Intrapreneurship versus entrepreneurship in high and low income countries. In R. Blackburn, F. Delmar, A. Fayolle, \& F. Welter (Eds.). Entrepreneurship, people and organisations. Frontiers in European entrepreneurship research. Cheltenham: Edward Elgar. doi: 10.4337/9781783478774.00012.

Bosma, N., Wennekers, S., \& Amorós, J. E. (2012). Global entrepreneurship monitor 2011 extended report: entrepreneurs and entrepreneurial employees across the globe. London: Global Entrepreneurship Research Association.

Boter, H., \& Lundstrom, A. (2006). SME perspectives on business support services. Journal of Small Business and Enterprise Development, 12(2). doi: $10.1108 / 14626000510594638$.

Brown, R., \& Mason, C. (2017). Looking inside the spiky bits: a critical review and conceptualisation of entrepreneurial ecosystems. Small Business Economics, 49(1). doi: 10.1007/s11187-017-9865-7.

Cohen, R., \& Swerdlik, M. (2010). Psychological testing and assessment. Boston: McGraw-Hill Higher Education.

Commission of the European Communities, Brussels (2001). Creating top-class business support services (Commission Staff Working Paper).

Daniluk, A. (2016). Conditions of cooperation between enterprises and business environment institutions using the Podlasie region as an example. Engineering Management in Production and Services, 8(4). doi: 10.1515/emj-2016-0029.

Delic, A., Alpeza, M., \& Peterka, O. (2012). Role of entrepreneurship support institutions in development of the economy of eastern Croatia - case of Centre for Entrepreneurship Osijek. Economy of Eastern Croatia Yesterday, Today, Tomorrow, 1 . 
Deloitte, (2012). DG enterprise - doing business in the digital age: the impact of new ICT developments in the global business landscape market analysis \& foresight scenarios report. Retrieved form http://www.iabeurope.eu/ files/5313/6852/1955/2012-1206_eu20study_market_analysis_and_foresight _scenarios_report_final_3.pdf.

Dillman, D. A., Smith, J., \& Christian, L. (2009). Internet, mail and mixed-mode surveys: the tailored design method. New York: John Wiley \& Sons.

Dubini, P. (1989). The influence of motivations and environment on business startups: some hints for public policies. Journal of Business Venturing, 4(1). doi: 10.1016/0883-9026(89)90031-1.

Dyer, M. L., \& Ross, A. C. (2008). Seeking advice in a dynamic and complex business environment: impact on the success of small firms. Journal of Development Entrepreneurship, 13(2). doi: 10.1142/S1084946708000892.

Ejdys, J., Ustinovicius, L., \& Stankevičienè, J. (2015). Innovative application of contemporary management methods in a knowledge-based economy interdisciplinarity in science. Journal of Business Economics and Management, 16(1). doi: 10.3846/16111699.2014.986192.

Feld, B. (2012). Startup communities: building an entrepreneurial ecosystem in your city. New Jersey: John Wiley \& Sons. doi: 10.1002/9781119204459.

Feldman, M. P. (2014). The character of innovative places: entrepreneurial strategy, economic development, and prosperity. Small Business Economics, 43(1). doi: 10.1007/s11187-014-9574-4.

Frese, M., Rousseau, D. M., \& Wiklund, J. (2014). The emergence of evidencebased entrepreneurship. Entrepreneurship theory and Practice, 38(2). doi: 10.1111/etap.12094.

Fritsch, M. (2013). New business formation and regional development - a survey and assessment of the evidence. Foundations and Trends in Entrepreneurship, 9. doi: 10.1561/0300000043.

Glabiszewski, W. Grego-Planer, D., \& Liczmańska-Kopcewicz, K. (2018). The impact of business environment institutions on the innovation of Polish small and medium-sized service enterprises. Economic and Environmental Studies, 18(2). doi: 10.25167/ees.2018.46.6.

Gnyawali, D. R., Madhaven, J., \& He, R. (2006). Impact of coopetition on firm competitive behaviour. An empirical examination. Journal of Management, 32(4). doi: 10.1177/0149206305284550.

Hakimin, Y. (Ed.) (2010). The utilisation of the government business support services: The senior adviser perspectives (Vol. 1). Kelantan: Universiti Malaysia Kelantan.

Henrekson, M., \& Sanandaji, T. (2014). Small business activity does not measure entrepreneurship. Proceedings of the National Academy of Sciences, 111(5). doi: 10.1073/pnas.1307204111. 
Hox J. J., de Leeuw, E. D., \& Dillman, D. A. (2008). Mixed mode surveys: when and why. In E. D. de Leeuw, J. J. Hox \& D.A. Dillman (Eds.). International handbook of survey methodology. New York, London: Lawrence Erlbaum Associates. doi: 10.4324/9780203843123.ch16.

Isenberg, D. (2011). The entrepreneurship ecosystem strategy as a new paradigm for economy policy: Principles for cultivating entrepreneurship. Babson Park, MA: Babson Entrepreneurship Ecosystem Project, Babson College.

Isenberg, D. J. (2010). How to start an entrepreneurial revolution. Harvard Business Review, 88(6).

Johannisson, B. (2011). Towards a practice theory of entrepreneuring. Small Business Economics, 36. doi: 10.1007/s11187-009-9212-8.

Kale, P., \& Singh, H. (2009). Managing strategic alliances: what do we know, and where do we go from here? Academy of Management Perspectives, 23. doi: 10.5465/amp.2009.43479263.

Kenney, M., \& Patton, D. (2005). Entrepreneurial geographies: support networks in three high-technology industries. Economic Geography, 81(2). doi: 10.1111/ j.1944-8287.2005.tb00265.x.

Korent, D., Vuković, K., \& Brčić, R. (2015). Entrepreneurial activity and regional development. Economic research-Ekonomska istraživanja, 28(1). doi: 10.1080 /1331677x.2015.1084237.

Lawson, C. (1997). Territorial clustering and high technology innovation: from industrial districts to innovative milieu. ESRC Centre for Business Research, University of Cambridge. Working Paper, 54.

Lazaric, N., \& Lorenz, E. (1997). Trust and organizational learning during interfirm cooperation. In N. Lazaric \& E. Lorenz (Eds.). The economics of trust and learning. Cheltenham: Edward Elgar.

Lewis, K., Massey, C., Ashby, M., Coetzer, A., \& Harris, C. (2007). Business assistance for SMEs: New Zealand owner-managers make their assessment. Journal of Small Business and Enterprise Development, 14(4). doi: 10.1108/14626000710832695.

Lorenz, E. (1996). Collective learning processes and the regional labour market. Unpublished research note, European Network on Networks, Collective Learning and RTD in Regionally-Clustered High Technology SMEs.

Lunnan, R., \& Haugland, S. A. (2008). Predicting and measuring alliance performance: a multidimensional analysis. Strategic Management Journal, 29. doi: 10.1002/smj.660.

Malecki, E. J. (2011). Connecting local entrepreneurial ecosystems to global innovation networks: open innovation, double networks and knowledge integration. International Journal of Entrepreneurship and Innovation Management, 14(1). doi: 10.1504/ijeim.2011.040821.

Mason, C., \& Brown, R. (2014). Entrepreneurial ecosystems and growth oriented entrepreneurship. Final Report to OECD, Paris, 30(1). 
Miller, M. B. (1995). Coefficient alpha: a basic introduction from the perspectives of classical test theory and structural equation modelling. Structural Equation Modelling, 2. doi: 10.1080/10705519509540013.

Moore, J. F. (1993). Predators and prey: a new ecology of competition. Harvard Business Review, 71(3).

Motoyama, Y., \& Knowlton, K. (2017). Examining the connections within the startup ecosystem: a case study of St. Louis. Entrepreneurship Research Journal, 7(1). doi: 10.1515/erj-2016-0011.

Motoyama, Y., Konczal, J., Bell-Masterson, J., \& Morelix, A. (2014). Think locally, act locally: building a robust entrepreneurial ecosystem. Kansas City: Ewing Marion Kauffman Fundation. doi: 10.2139/ssrn.2425675.

Napier, G., \& Hansen, C. (2011). Ecosystems for young scalable firms. FORA Group. February.

Patton, D., \& Kenney, M. (2005). The spatial configuration of the entrepreneurial support network for the semiconductor industry. $R \& D$ Management, 35(1). doi: 10.1111/j.1467-9310.2005.00368.x.

Rasmussen, K. (2008). Halo effect. In N. J. Salkind \& K. Rasmussen (Eds.). Encyclopedia of educational psychology (Vol. 1). Thousand Oaks, CA: Sage Publications, Inc.

Rosted, J. (2012). Understanding business ecosystems. FORA Group.

Roundy, P. T., Brockman, B. K., \& Bradshaw, M. (2017). The resilience of entrepreneurial ecosystems. Journal of Business Venturing Insights, 8. doi: 10.1016/j.jbvi.2017.08.002.

Roundy, P., Bradshaw, M., \& Brockman, B. (2016). Venturing towards the edge of chaos: a complex adaptive systems approach to entrepreneurial ecosystems. In United States Association for Small Business and Entrepreneurship. Conference proceedings. Boca Raton: United States Association for Small Business and Entrepreneurship.

Schneider, F. W., Gruman, J. A., \& Coutts, L. M. (2012). Applied social psychology. California.

Shane, S. (2009). Why encouraging more people to become entrepreneurs is bad public policy. Small Business Economics, 33. doi: 10.1007/s11187-009-9215-5.

Spigel, B. (2017). The relational organization of entrepreneurial ecosystems. Entrepreneurship Theory and Practice, 41(1). doi: 10.1111/etap.12167.

Stam, E. (2013). Entrepreneurial ecosystem. NL: miracle or paradox. Paper presented at OECD LEED Programme Workshop on Entrepreneurial Ecosystems and Growth-oriented Entrepreneurship, The Hague.

Stam, E., \& Bosma, N. (2015). Local policies for high-growth firms. In D. Audretsch, A. Link, \& M. Walshok (Eds.). Oxford handbook of local competitiveness. Oxford: Oxford University Press. doi: 10.1093/oxfordhb/97801999 93307.013.14. 
Stam, E. (2014). The Dutch entrepreneurial ecosystem. SSRN doi: 10.2139/ ssrn.2473475.

Stam, E. (2015). Entrepreneurial ecosystems and regional policy: a sympathetic critique. European Planning Studies, 23(9). doi: 10.1080/09654313. 2015.1061484.

Stam, E., \& Spigel, B. (2016). Entrepreneurial ecosystems and regional policy. Sage handbook for entrepreneurship and small business. London: Sage. doi: 10.4135/9781473984080.n21.

Stam, E., Suddle, K., Hessels, J., \& Van Stel, A. (2009). High-growth entrepreneurs, public policies and economic growth. In J. Leitao \& R. Baptista (Eds.). Public policies for fostering entrepreneurship: a European perspective. New York: Springer. doi: 10.1007/978-1-4419-0249-8_5.

Tavakol, M., \& Dennick. R. (2011). Making sense of Cronbach's alpha. International Journal of Medical Education, 2. doi:10.5116/ijme.4dfb.8dfd.

Thorndike, E. L. (1920). A constant error in psychological ratings. Journal of Applied Psychology, 4(1). doi: 10.1037/h0071663.

Tongco, M. D. C. (2007). Purposive sampling as a tool for informant selection. Ethnobotany Research and Applications, 5. doi: 10.17348/era.5.0.147158.

Tsvetkova, A. (2015). Innovation, entrepreneurship, and metropolitan economic performance: empirical test of recent theoretical propositions. Economic Development Quarterly, 29(4). doi: 10.1177/0891242415581398.

Walker, B., Holling, C. S., Carpenter, S. R., \& Kinzig, A. (2004). Resilience, adaptability and transformability in social-ecological systems. Ecology and Society, 9(2). doi: 10.5751/es-00650-090205.

World Economic Forum (2013). Entrepreneurial Ecosystems around the Globe and Company Growth Dynamics. World Economic Forum, Cologny, Switzerland.

Zacharakis, A. L., Shepherd, D. A., \& Coombs, J. E. (2003). The development of venture-capital-backed internet companies: an ecosystem perspective. Journal of Business Venturing, 18(2). doi: 10.1016/s0883-9026(02)00084-8.

Zhang, Y., \& Li, H. (2010). Innovation search of new ventures in a technology cluster: the role of ties with service intermediaries. Strategic Management Journal, 31(1). doi: 10.1002/smj.806. 


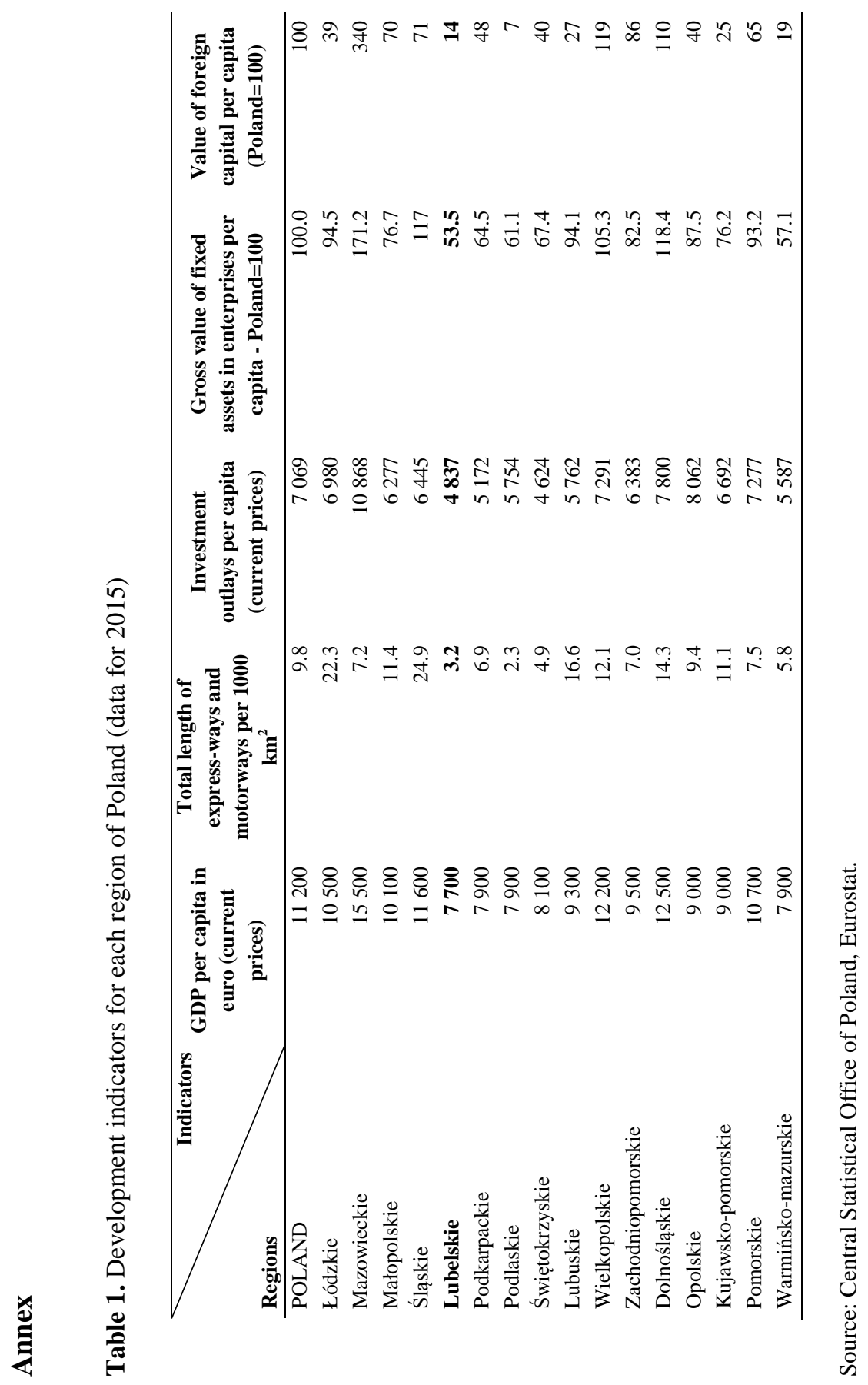


Tabela 2. Characteristics of the sample $(n=386)$

\begin{tabular}{lcc}
\hline Characteristics & Number of enterprises & {$[\%]$} \\
\hline To 5 years & Age & \\
From 5 to 10 lat & 97 & 25.13 \\
Above 10 years & 147 & 38.08 \\
\hline & 142 & 36.79 \\
\hline Micro & Employment & 89.38 \\
Small & 345 & 9.07 \\
Medium & 35 & 1.04 \\
Huge & 4 & 0.52 \\
\hline & 2 & \\
\hline Local & Range of activity & 67.88 \\
Regional & 262 & 20.73 \\
Domestic & 80 & 5.96 \\
International & 23 & 5.44 \\
\hline
\end{tabular}




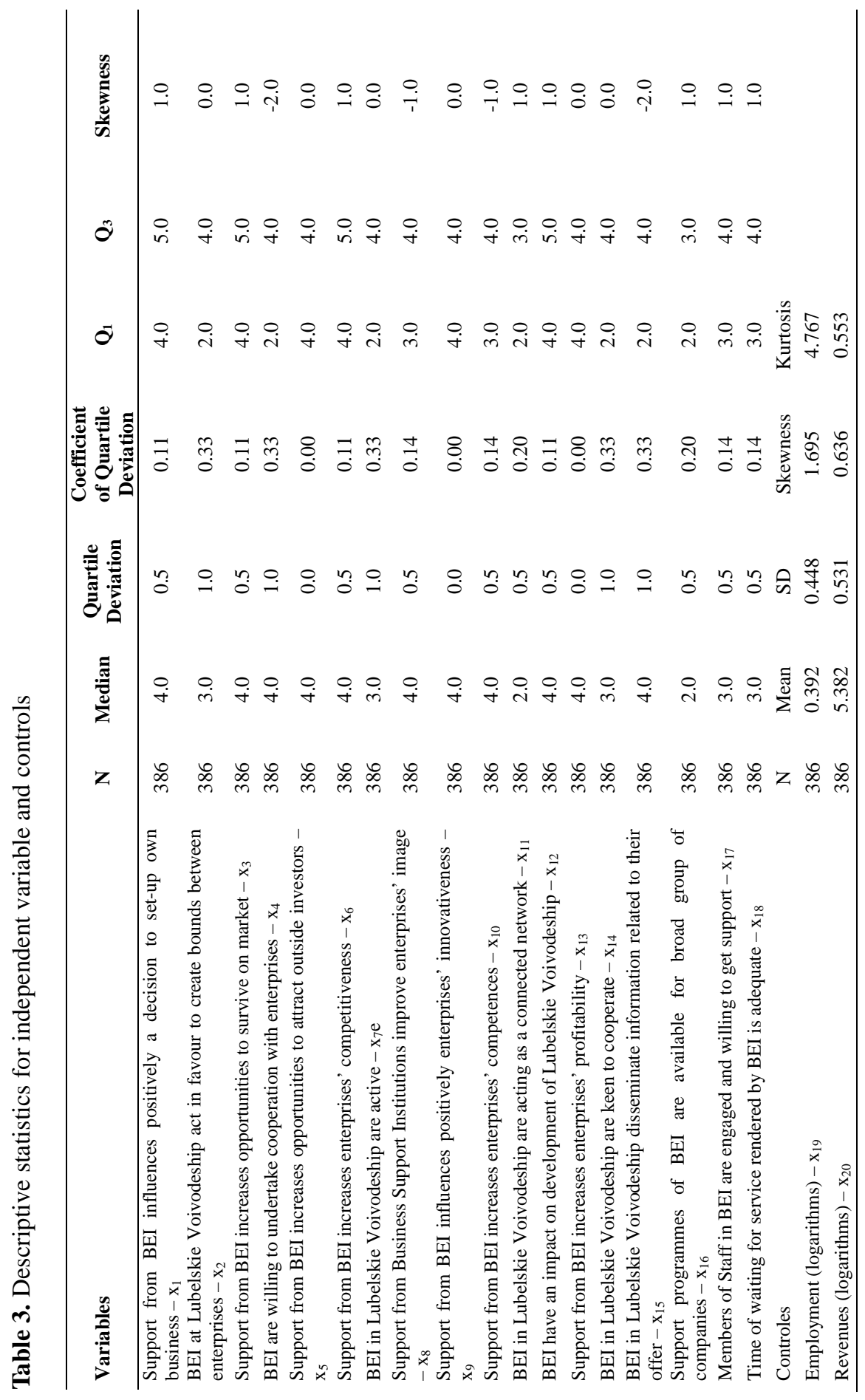




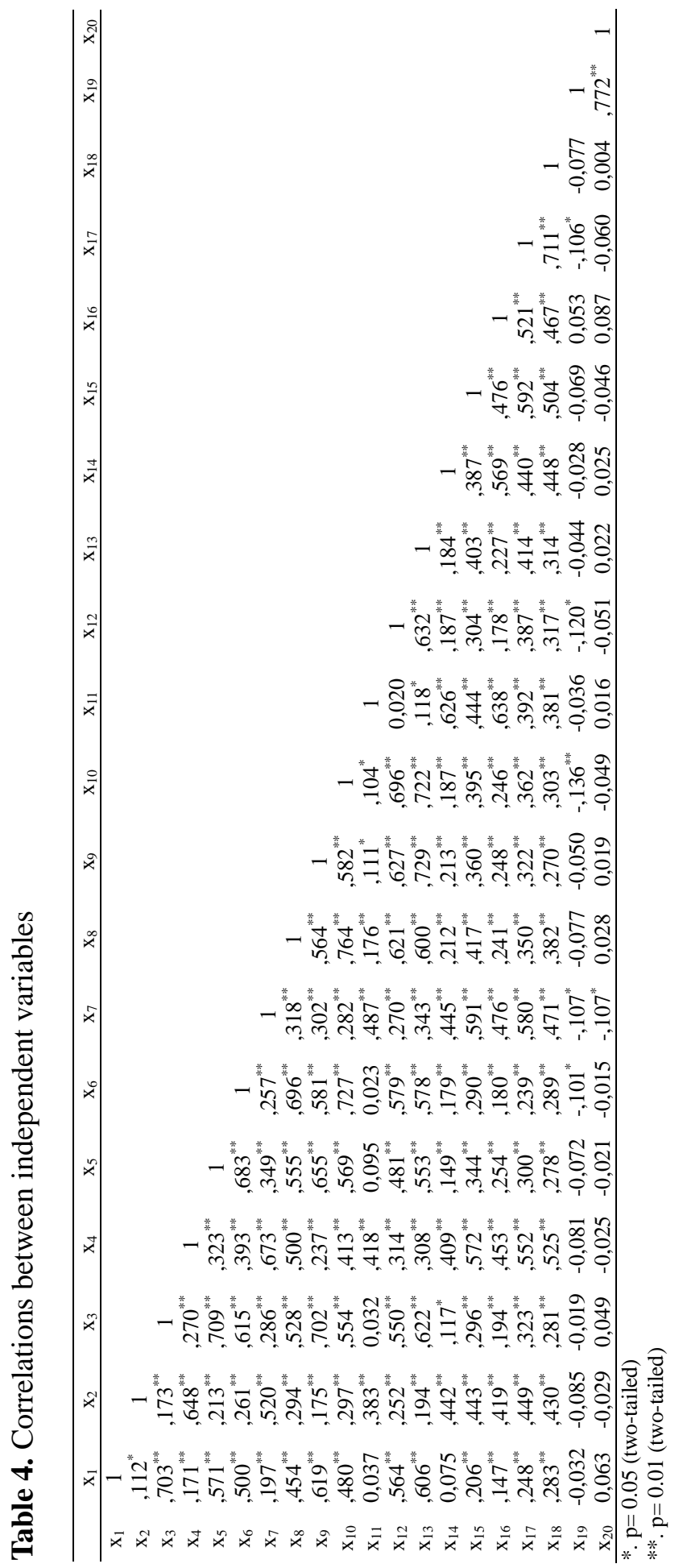


Table 5. Logit regression model

\begin{tabular}{|c|c|c|c|c|c|c|c|}
\hline \multirow{2}{*}{ Variables } & \multirow{2}{*}{ B } & \multirow{2}{*}{$\begin{array}{l}\text { Standard } \\
\text { error }\end{array}$} & \multirow{2}{*}{ Wald } & \multirow{2}{*}{$\mathbf{p}$} & \multirow{2}{*}{$\operatorname{Exp}(B)$} & \multicolumn{2}{|c|}{$\begin{array}{l}\text { 95\% confidence interval for } \\
\operatorname{EXP}(B)\end{array}$} \\
\hline & & & & & & Lower limit & Upper limit \\
\hline \multicolumn{8}{|l|}{ IV } \\
\hline $\mathrm{x}_{1}$ & 1.346 & 0.295 & 20.856 & 0.000 & 3.843 & 2.157 & 6.849 \\
\hline $\mathrm{x}_{2}$ & 0.458 & 0.171 & 7.161 & 0.007 & 1.581 & 1.130 & 2.211 \\
\hline $\mathrm{x}_{3}$ & 0.723 & 0.338 & 4.578 & 0.032 & 2.061 & 1.063 & 3.998 \\
\hline $\mathrm{x}_{4}$ & -0.159 & 0.213 & 0.558 & 0.455 & 0.853 & 0.562 & 1.294 \\
\hline $\mathrm{x}_{5}$ & -1.388 & 0.320 & 18.823 & 0.000 & 0.250 & 0.133 & 0.467 \\
\hline $\mathrm{x}_{6}$ & 0.360 & 0.277 & 1.688 & 0.194 & 1.433 & 0.833 & 2.465 \\
\hline $\mathrm{x}_{7}$ & 0.173 & 0.202 & 0.739 & 0.390 & 1.189 & 0.801 & 1.766 \\
\hline $\mathrm{x}_{8}$ & 0.024 & 0.275 & 0.008 & 0.930 & 1.024 & 0.598 & 1.756 \\
\hline $\mathrm{X}_{9}$ & 1.414 & 0.301 & 4.889 & 0.027 & 1.513 & 0.838 & 2.732 \\
\hline $\mathrm{x}_{10}$ & -0.017 & 0.310 & 0.003 & 0.956 & 0.983 & 0.535 & 1.806 \\
\hline $\mathrm{x}_{11}$ & -0.260 & 0.200 & 1.679 & 0.195 & 0.771 & 0.521 & 1.142 \\
\hline $\mathrm{x}_{12}$ & -1.398 & 0.253 & 4.483 & 0.034 & 0.672 & 0.409 & 1.102 \\
\hline $\mathrm{x}_{13}$ & -0.154 & 0.305 & 0.254 & 0.614 & 0.858 & 0.472 & 1.558 \\
\hline $\mathrm{x}_{14}$ & -0.407 & 0.203 & 4.032 & 0.045 & 0.666 & 0.448 & 0.990 \\
\hline $\mathrm{x}_{15}$ & -0.016 & 0.195 & 0.007 & 0.935 & 0.984 & 0.672 & 1.442 \\
\hline $\mathrm{x}_{16}$ & 0.429 & 0.181 & 5.639 & 0.018 & 1.535 & 1.078 & 2.187 \\
\hline $\mathrm{x}_{17}$ & 1.210 & 0.280 & 18.662 & 0.000 & 3.352 & 1.936 & 5.803 \\
\hline $\mathrm{x}_{18}$ & -0.269 & 0.269 & 0.997 & 0.318 & 0.764 & 0.451 & 1.295 \\
\hline \multicolumn{8}{|l|}{ Controles } \\
\hline $\mathrm{x}_{19}$ & 0.196 & 0.454 & 0.186 & 0.666 & 1.216 & 0.499 & 2.962 \\
\hline $\mathrm{x}_{20}$ & -0.290 & 0.400 & 0.524 & 0.469 & 0.748 & 0.342 & 1.640 \\
\hline Constant & -7.391 & 2.188 & 11.406 & 0.001 & 0.001 & & \\
\hline
\end{tabular}

